Fisheries Oceanography

November 2016, Volume 25, Issue 6, Pages 582-597

http://dx.doi.org/10.1111/fog.12174

Achimer

http://archimer.ifremer.fr/doc/00346/45676/

(c) 2016 John Wiley \& Sons Ltd

\title{
Size, permeability and buoyancy of anchovy (Engraulis Encrasicolus) and sardine (Sardina Pilchardus) eggs in relation to their physical environment in the Bay of Biscay
}

\author{
Huret Martin ${ }^{1,{ }^{*}}$, Bourriau Paul ${ }^{2}$, Gatti Paul ${ }^{1}$, Dumas Franck ${ }^{3}$, Petitgas Pierre ${ }^{2}$
}

${ }^{1}$ Ifremer,STH/LBH; B.P. 70 Plouzané 29280, France

${ }^{2}$ Ifremer,EMH; rue de l'île d'Yeu BP 2110544311 Nantes Cedex 03 ,France

${ }^{3}$ Ifremer,DYNECO-PHYSED; B.P. 70 Plouzané 29280 ,France

* Corresponding author : Martin Huret, email address : martin.huret@ifremer.fr

\begin{abstract}
:
The size and specific gravity of eggs of marine pelagic fish partly determine their dispersal and survival. Using an original dataset of anchovy and sardine eggs, sampled in spring over the last decade in the Bay of Biscay, we provide a parameterization of these properties on ambient water temperature and salinity. We used the density gradient column for measurement of egg specific gravity. The column was also filled with homogeneous water for sinking velocity experiments. For anchovy, these experiments confirm that the effect of egg permeability through the chorion could be neglected when modelling sinking, while it has to be considered for sardine, its perivitelline space representing $78.6 \%( \pm 6.2 \%)$ of the total egg volume, as opposed to $5-10 \%$ for most teleosts species. We estimated a coefficient of permeability of the chorion of $0.0038 \mathrm{~mm} \mathrm{~s}-1$. However, permeability should not affect the measurement of sardine egg specific gravity in a gradient column, provided a minimum duration before reading is respected for equilibrium to be reached. In relation to their environment, we found that the egg specific gravity is largely determined by sea surface salinity for both species, whereas egg size is weakly but significantly impacted by temperature, for sardine only. On average, the estimated difference in specific gravity between egg and surface water is $-0.92 \sigma \mathrm{T}$ for anchovy and $-1.06 \sigma \mathrm{T}$ for sardine. The detailed parameterization of the relationship between eggs and water properties should prove useful, in particular to modellers dealing with the dispersal of fish early life stages.
\end{abstract}

Keywords: Keywords: anchovy, Bay of Biscay, density gradient column, egg buoyancy, egg permeability, egg size, sardine 
INTRODUCTION

45 Fish egg properties have a fundamental impact on their dispersal and on the survival of 46 initial stages of life. Size and specific gravity are key among those properties. Size may be 47 related to recruitment to late larval stage (Chambers, 1997) through its potential link with 48 egg quality, that will determine the size and capacity of young larvae to be active, grow, 49 and survive, or by direct relationship between size and mortality. Specific gravity is the 50 main driver of the egg vertical distribution (Sundby and Kristiansen, 2015), defining the

51 water mass in which they will be advected, which eventually determines connectivity 52 patterns from spawning areas.

For analysis and integration of these dispersal processes, models of egg vertical

54 distribution have been developed with several objectives. A first one is the interpretation of 55 eggs distribution for better ecological understanding (Sundby, 1983; Adlandsvik et al., 56 2001). A second one is management, with methods of stock assessment based on total egg 57 abundance (Petitgas et al., 2009). In the case of CUFES sampling (Continuous Underway 58 Fish Egg Sampler, Checkley Jr et al., 1997) an extrapolation is required over the water 59 column from observed surface abundance (Boyra et al., 2003; Curtis et al., 2007). In a third 60 objective, vertical distribution models are also embedded in three dimensional circulation

61 models to study connectivity patterns between spawning areas and later stages habitat and

62 nurseries (Parada et al., 2003; Huret et al., 2010; Ospina-Álvarez et al., 2012).

63 In these models, egg specific gravity, and to a lesser extent size, are the most 64 sensitive biological parameters (Petitgas et al., 2006), in addition to the water column 65 physical properties. For most species there is a lack of descriptive information on egg 66 properties and mostly on what control their variability in time and space. They vary 
67 between and within species, and seem to be under the direct or indirect influence of the

68 external environment during oogenesis.

69 The size of eggs spans over a well described range at the species level (Munk and

70 Nielsen, 2005). Besides a natural phenotypic variance on a genetic basis, a maternal effect

71 was also demonstrated, with larger fish spawning larger eggs for cod (Kjesbu, 1989; Vallin

72 and Nissling, 2000) or haddock (Trippel and Neil, 2004). Similar pattern has been observed

73 with maternal condition, together with (Marteinsdottir and Steinarsson, 1998), or instead of

74 mother size (Chambers and Waiwood, 1996). Egg size may also be affected by the batch

75 number within a spawning season, with a decrease as the season advances (Kjesbu et al.,

76 1992; Trippel and Neil, 2004; Vallin and Nissling, 2000). But size may also be under direct

77 influence of temperature during oogenesis from a decoupling between growth and

78 development in the response to temperature (Chambers, 1997).

79 The specific gravity of eggs also shows some variability. The osmolarity of the

80 embryo and yolk is constant and equal to the one of maternal plasma (Davenport et al.,

81 1981), with variability of specific gravity mostly arising from variable fluid content after

82 hydration process (Craik and Harvey, 1987). Through this maternal control, specific

83 adaptations to regional marked hydrography differences were observed, this is the case

84 between brackish Baltic waters and marine Atlantic waters for flounder (Solemdal, 1967) or

85 cod (Thorsen et al., 1996), or between Mediterranean and Bay of Biscay waters for

86 anchovy (Ospina-Álvarez et al., 2012). But more subtly, some adaptations were also

87 mentioned within a region or population, again seemingly under indirect environment

88 control through the maternal plasma. Coombs et al., (1985) noted that sardine eggs in the

89 Bay of Biscay were always positively buoyant relatively to sampled sea water. In the same

90 region, Goarant et al. (2007) observed a significant correlation between the egg specific 
91 gravity of anchovy and the salinity at sampling station. Additionally, the egg specific

92 gravity may slightly evolves throughout development with processes detailed in Jung et al.

93 (2014). This evolution pattern was described for both sardine (Coombs et al., 1985) and

94 anchovy (Ospina-Álvarez et al., 2012).

$95 \quad$ Our two species of interest in this study display strong distinctive features (Munk 96 and Nielsen, 2005) despite their taxonomic proximity. This make them ideal case studies

97 for comparison, as well as good candidates for generalisation of our results to other species.

98 Anchovy (Engraulis encrasicolus) eggs have a prolate spheroid shape. The ellipsoid shape

99 may have an effect on its sinking velocity depending on its orientation as compared to a

100 sphere of equivalent volume (Coombs et al., 2004), even if this effect was estimated small

101 for anchovy eggs (Boyra et al., 2003; Petitgas et al., 2006). Sardine (Sardina pilchardus)

102 eggs are large with an unusually large perivitelline space, occupying about $80 \%$ of the total

103 egg volume whereas it is generally lower than $10 \%$ for most other species, among them

104 anchovy. Experiments with the density gradient column (Coombs, 1981) suggest that this

105 could have some effects on observed sinking velocity (Coombs et al., 2004) and more

106 embarrassing on measured specific gravity (Coombs et al., 1985). The chorion, the outer

107 membrane separating the perivitelline space from the surroundings, is described as being

108 permeable to salt and water (Davenport et al., 1981). Thus, egg specific gravity is only

109 determined by the ovoplasm and the degree of hydrolysation of yolk prior to ovulation

110 (Craik and Harvey, 1987), as well as by the amount of material invested in the chorion

111 (Jung et al., 2014). As the ovoplasm regulates its osmolarity (Davenport et al., 1981), the

112 measured egg specific gravity should not be affected by the exchange through the chorion.

113 This is true provided that a sufficient duration is accorded to the experiment for an

114 equilibrium between the perivitelline space and the surrounding water to be reached, at the 
115 equivalent depth of the ovoplasm plus chorion specific gravity.

116 Considering the importance of egg properties -size and specific gravity- on their in-

117 situ fate, and that those properties are under the influence of seawater physical properties,

118 the primary objective of the present study is to provide description and parameterisation of

119 those relationships for anchovy and sardine in the Bay of Biscay. We used a large dataset of

120 observed egg size and specific gravity in the Bay of Biscay, with an update for anchovy and

121 a fully new dataset for sardine. The density gradient column of Coombs (1981) was used

122 for both specific gravity and sinking velocity experiments. As accurate measurement of

123 sardine egg specific gravity seems to remain challenging, the sinking experiments were

124 performed in order to better quantify the effect of egg permeability, which constitutes a

125 secondary objective of the paper. Besides providing useful parameterisation to models of

126 egg dispersal, the experiments and analysis we conducted restore consistency in the

127 ambiguous literature on quality of specific gravity measurements of sardine eggs, as well as

128 in the non explained higher correlation found in Goarant et al. (2007) between anchovy

129 eggs and sea surface salinity, rather than with sea surface density. 


\section{Egg sampling}

133 Eggs were sampled during the PELGAS small pelagic survey in the Bay of Biscay in May,

134 onboard the R/V Thalassa, from 2005 to 2014 for anchovy (number of stations $=62$ ) and

135 for 2009 to 2015 for sardine $(n=27)$. Sampling stations are shown on Fig.1. They are

136 located from the south of the bay mostly for anchovy, to the bay of Douarnenez at the tip of

137 Brittany $\left(48^{\circ} \mathrm{N}-4.5^{\circ} \mathrm{W}\right)$ for sardine, the locations being representative of the main areas of

138 distribution of the eggs of both species. They also cover a large variability of environmental

139 conditions, with a north to south temperature gradient in spring and a coast to offshore

140 salinity gradient in relation to the Gironde and Loire river plumes. Eggs were sampled

141 following the same methodology as Goarant et al. (2007), using the 'Carré Net' (Bourriau,

142 1991) hauled at a maximum speed of 2 knots in the mixed layer for a maximum duration of

$14310 \mathrm{~min}$. Hauling allowed a sufficient number of eggs to be collected at stations for latter

144 size measurement, specific gravity as well as sinking experiments. The counterpart is

145 certainly a higher number of dead or moribund eggs in the sample. Precautions were taken

146 to avoid any bias from including damaged eggs in the experiments : first by gently taking

147 the sample from the collector to the container, second the sample was gently stirred to

148 ensure selecting only the most buoyant eggs, and third by not considering the remaining

149 moribund eggs when in the density gradient column, where they appeared opaque and sank

150 quickly to the bottom before any height reading were performed.

151 At each sampling station a CTD (SBE19+v2, Seabird) cast was performed

152 providing water temperature, salinity and then density profiles. For correlation with egg

153 specific gravity, the sea water properties were averaged between 3 and $5 \mathrm{~m}$ to obtain 
154 representative values of the surface mixed-layer, where the majority of the eggs are

155 expected to be found (Boyra et al., 2003; Coombs et al., 2004). 3m is the minimum depth

156 for which CTD values are available at all stations. Shallower, swell often hinder the correct

157 quality of data acquisition.

158

159 Egg size measurements

160 The eggs were measured onboard with a binocular 50x magnification, offering an accuracy

161 of $0.1 \mathrm{~mm}$. Anchovy egg is a prolate spheroid then the two dimensions were measured. For

162 sardine, both egg diameter and vitellus diameter were measured even if the latter was

163 performed only in the case early developmental stages of eggs were available, i.e. stages 1

164 to 3 of the classification proposed by Ahlstrom (1943), thus until beginning of gastrulation.

16520 eggs were measured per stations.

166

167 Egg specific gravity measurements

168 We used the density gradient column of Coombs (1981) onboard the research vessel and

169 followed the calibration and reading procedures detailed in Goarant et al. (2007). Reported

170 accuracy in specific gravity is $0.04 \sigma_{\mathrm{T}}$ (Coombs, 1981). 50 eggs were released per

171 experiment in the column to derive specific gravity average and standard deviation. Early

172 developmental stages of eggs were chosen, i.e. until beginning of gastrulation or stage 1 to

1733 following the classification of Moser and Ahlstrom (1985) for anchovy and Ahlstrom

174 (1943) for sardine. In any case late stages (from stage VII) were never selected since those

175 have their specific gravity significantly increased before hatching (Coombs et al., 1985;

176 Ospina-Álvarez et al., 2012). During the first years until 2008, temperature in the density

177 column gradient was thermostatically controlled at $15^{\circ} \mathrm{C}$. However, since temperature has 
178 an effect on egg specific gravity and egg thermal expansion is not easily measured (Sundby

179 and Kristiansen, 2015, but see Coombs et al., 1985), from 2009 on, the density column

180 temperature was set at the temperature of the sea surface at station location, thus limiting

181 the effect of variation in egg temperature on the experiment results. To correct for this

182 effect in the earliest years of our sampling from 2005 to 2008, we calculated the equivalent

183 density at sea surface considering the temperature of the gradient column experiment. A

184 minimum of 4 specific gravity readings were performed in the column for the 50 eggs from

185 each station, with an interval of 1 h between readings. In the case of sardine we waited for a

186 minimum of $1 \mathrm{~h}$ before the first reading, as egg sinking velocity, and thus reaching

187 equilibrium, can be slow (see fig. 4 in Coombs, 1981) as compared to anchovy, due to some

188 exchange between the perivitelline space and the low density water at the top of the

189 column.

190

\section{Egg sinking velocity}

192 The density gradient column was also used to measure sinking velocities of the eggs. For

193 those experiments conducted during PELGAS surveys 2012 to 2015, columns of

194 homogeneous density were prepared with well mixed salted water. Coombs et al. (1990)

195 proposed to use sea water to measure egg buoyancy through ascent velocity in an

196 homogeneous column. The objective here is to better assess the sinking (or ascent) velocity

197 model and assess the permeability of sardine eggs. The column was then filled with a salted

198 solution of density below or close to $22 \sigma_{\mathrm{T}}$, a value a priori significantly lower than the

199 surface water densities in our area in which eggs are expected to be approximately neutrally

200 buoyant. The difference in specific gravity between eggs and homogeneous column can not

201 be constant since the columns are prepared before sampling, when the seawater density at 
202 station is not known. This difference ranged between 1.6 and $3.6 \sigma_{\mathrm{T}}$, and the eggs were 203 travelling down the column in a reasonably small amount of time, although not too fast to

204 allow measurement. Eventually the absolute difference does not have any impact on the 205 experiment itself, provided that the column density is correctly measured, which was done 206 with a densimeter (Richter \& Wiese) with $0.1 \sigma_{\mathrm{T}}$ accuracy. An homogeneous column was 207 preferred to a density gradient column as used in Coombs et al. (2004) because of the 208 longer distance and time traveled by the eggs in the case of homogeneity, allowing more 209 velocity measurements per egg leading eventually to higher accuracy. For each of these 210 experiments, 6 for anchovy and 4 for sardine, 10 early stage eggs were introduced at the top

211 of the density column after size measurement, and time recorded when egg passed each 212 graduated centimeter. In parallel a classical density gradient column was performed to 213 assess the average specific gravity and its variability at the corresponding sampling station.

214 To assess the observed sinking velocities, we used an analytical model of terminal 215 velocity. Sundby (1983) first proposed the combination of Stokes's equation, with 216 Dalavalle's one (Dalavalle, 1948) when Reynold's number is higher than 0.5. We used the 217 equation of Denny (1993) who proposed a unique function allowing for continuous 218 transition and valid for Reynold's number from low to values as high as $\mathrm{Re}=100000$. It 219 also avoids the use of a calibration constant necessary in Dalavalle's parameterisation. 220 Denny's equation is given as:

221

$$
0=0.2 \mathrm{v}_{t}^{2}+\frac{6 v \mathrm{v}_{t}}{r}+\frac{3 \mathrm{v}_{t}^{2}}{1+\sqrt{2 r \mathrm{v}_{t} / v}}-\frac{4 \rho_{e} r \mathrm{~g}}{3 \rho_{f}}
$$

224 with $v_{t}$ the terminal velocity, $v$ the kinematic viscosity of the water, $r$ the radius of the 
225 sphere, g the gravity acceleration, $\rho_{\mathrm{f}}$ the density of the water, and $\rho_{\mathrm{e}}$ the egg specific

226 gravity. This equation is solved for any difference of specific gravity between egg and 227 surrounding water. It is more time consuming than Sundby (1983) solution, although only

228 for the computer, but more accurate especially for high Reynold's number which can be the 229 case in our experimental setup.

230 The kinematic viscosity $v=\mu / \rho_{\mathrm{f}}$, with $\mu$ the dynamic viscosity of water, is

231 calculated from the equation proposed in Adlandsvik (1998):

232

233

$$
\mu=10^{-3} *\left(1.7915-0.0538 * \mathrm{~T}+0.0007 * \mathrm{~T}^{2}+0.0023 * \mathrm{~S}\right),
$$

234

235 with T temperature and S salinity of water, which approximates the typically used table 236 chart with a relative error of only 1.7\% (Adlandsvik, 1998).

237 The sinking velocity of a prolate spheroid is affected by the ratio of its axis as well 238 as its orientation (see Hutchinson (1967). The ratio of the major to minor axis measured in 239 our study for an anchovy egg is in the range 1.5-2.73 (mean=2.16, see Results section). 240 Denny (1993, p.64) gives a formulation for the correction of forces acting on an ellipsoid 241 instead of a sphere, but only for major axis >> minor axis. Hutchinson (1967, p262) 242 provides a more generic correction for various ratio and orientation when sinking. The 243 resulting correction ranges between 1/0.955 and 1/1.2 comparatively to the equivalent 244 sphere, thus slightly higher velocities when in the direction of the major axis and 245 potentially lower velocities when in other orientation. These considerations were assessed 246 for sinking experiments of anchovy eggs.

247 The egg specific gravity can be expressed from the specific gravity ( $\rho)$ and volume 
248 (V) of its respective parts (embryo + yolk, chorion -ch-, and perivitelline space -pvs-)

249 following Jung et al. (2014) :

250

$251 \rho_{e}=\left(\rho_{e m b+y o l k} \times V_{e m b+y o l k}+\rho_{c h} \times V_{c h}+\rho_{p v s} \times V_{p v s}\right) / V_{e}$

252

253 with Ve the total egg volume. After oocyte hydration, specific gravity of embryo and yolk is

254 known to vary only little. After fertilisation, volume of perivitelline space increases to reach

255 its final volume, but free exchange of salt and water by diffusion are still possible through

256 the chorion between this compartment of the egg and the external medium. Gathering

257 variable and invariable components of the eggs, depending on their potential change of 258 specific gravity and volume with time, gives :

259

260

$\rho_{e}=\left(\rho_{e m b+y o l k+c h} \times\left(V_{e m b+y o l k}+V_{c h}\right)+\rho_{p v s} \times V_{p v s}\right) / V_{e}$

261

262

The chorion volume could not be measured on living eggs onboard, but is assumed

to be small for teleosts (1-5\% of total egg volume, Sundby and Kristiansen, 2015) and

constant throughout development (Jung et al., 2014). It was, thus, neglected in the equation.

265 The chorion mass, however, as it is the heaviest component of the egg (Sundby and

266 Kristiansen, 2015), is included in the invariable component of the egg $\rho_{\text {emb+yolk }+ \text { ch }}$.

267 For eggs of most species, perivitelline space is within the range $5-10 \%$ of the total 268 egg volume, and the effect of diffusion with the external medium is limited on the egg 269 specific gravity. But for sardine, this volume is close to $80 \%$ (see result section), and then

270 variation of $\rho_{\text {pvs }}$ from exchange of salt and water through the chorion can have a large effect 
271 on the egg specific gravity. To take this effect into account, we implemented a diffusion

272 equation in the sinking velocity model for sardine, to adjust $\rho_{\text {pvs }}$ to the density of the egg

273 surrounding water. Based on Fick's diffusion equation of a solute through a membrane,

274 Coombs et al. (2004) proposed the following equation for the change in specific gravity of

275 the perivitelline space :

276

277

$\frac{\partial \rho_{p v s}}{\partial t}=P_{e} \times\left(\rho_{f}-\rho_{p v s}\right)$ with $P_{e}=\frac{S_{c h}}{V_{p v s}} \times P_{m}$

278

279 with $\mathrm{P}_{\mathrm{e}}$ the egg permeability, $\mathrm{P}_{\mathrm{m}}$ the chorion permeability, $\mathrm{S}_{\mathrm{ch}}$ the surface of exchange of the

280 chorion and $\rho_{\mathrm{f}}$ the density of the fluid surrounding the egg.

281 The model sinking velocities, or egg positions in the column through time, were

282 compared to observed egg positions in the homogeneous columns. For anchovy only Eq.1

283 was necessary, with $\rho_{\mathrm{e}}$ the egg specific gravity available from measurements in the

284 associated gradient column. For sardine, the combination of Eq.1, 4 and 5 was necessary to

285 consider the adjustment of egg specific gravity to surrounding water through time while

286 sinking. In equation $5, \mathrm{P}_{\mathrm{m}}$ is unknown. Another uncertainty is the effective specific gravity

287 of the egg when in-situ, or at initial time when set in an experimental column, since it is

288 mentioned that the measured specific gravity using the gradient column may be

289 underestimated for sardine (Coombs et al., 2004), again due to the adaptation of the

290 perivitelline space specific gravity during the experiment. At this initial time $t_{0}$, Equation 4

291 can be decomposed as :

292 
$\rho_{e}\left(t_{0}\right)=\left(\left(\rho_{e}^{m}+\delta_{\text {eyc }}\right) \times V_{\text {emb+yolk }}+\left(\rho_{e}^{m}+\delta_{\text {eyc }}+\delta_{\text {pvs }}\right) \times V_{p v s}\right) / V_{e}$

295 with $\rho_{\mathrm{e}}^{\mathrm{m}}$ the measured average egg specific gravity at the station, $\delta$ eyc the residual specific 296 gravity of the egg from the station average, and $\delta p v s$ the difference between actual egg 297 specific gravity $\left(\rho_{\mathrm{e}}^{\mathrm{m}}+\right.$ Seyc$)$ and specific gravity of perivitelline space at $\mathrm{t}_{0}$.

298 For each egg of the 4 experiments of sinking rate performed on sardine, an 299 estimation of the three parameters $\mathrm{P}_{\mathrm{m}}, \delta$ pvs and $\delta$ eyc was performed, by minimisation of the 300 difference in egg position through time between model results and data. The $\mathrm{R}$ routine 301 optim with the bounded Quasi-Newton method (Byrd et al., 1995) was used for 302 optimisation. We then analysed the distribution of the values of estimated parameters for 303 the whole set of eggs. 


\section{RESULTS}

310 Egg size

311 Average egg size and associated variability, both on population (all measured eggs) and

312 sample (station) scale, are given in table 1. For sardine, one interesting feature is the large

313 size of the perivitelline space, calculated here on average to be $78.6 \%(+/-6.2 \%)$ of the total

314 egg volume, with unmeasured chorion volume assumed to be part of the perivitelline space.

315 In an attempt to correlate egg size with environmental covariates, we could not find

316 any significant relationship for anchovy (Fig.2). For sardine, a significant correlation

$317(\mathrm{p}<0.05)$ was found between both egg and vitellus sizes and sea surface temperature (Fig.3)

318 while there was no relation between the calculated perivitelline space (total volume minus

319 vitellus volume) and temperature. The warmer the water, the smaller the eggs and vitellus,

320 with an estimated percentage of decrease of $7-8 \%$ between 12 and $17^{\circ} \mathrm{C}$. We mention here

321 that vitellus size was positively correlated $(\mathrm{p}<0.01, \mathrm{n}=12)$ to egg size. Other tested

322 covariates, the sea surface salinity and the egg specific gravity itself, were not significant

323 factors of the variation in egg size (Table 2).

325 Sinking velocity

326 Sinking velocity experiments performed on anchovy revealed relatively constant sinking 327 rate through the homogeneous density columns looking at their position over time (Fig. 4).

328 Despite some variability at the individual level, with some eggs slowing down (e.g. the 329 fastest eggs at station R0295) or accelerating (e.g. the slowest eggs at station Q0559), this

330 was only temporary and no general trend of changing speed with time could be noticed

331 over the whole set of experiments. The large majority of eggs were sinking in the direction 
332 of their major axis. This is because the fluid in the perivitteline space is always heavier than

333 that of embryo and yolk and hence give the eggs a balanced orientation. Dead or dying

334 embryos, however, stop osmoregulation and get as heavy as the perivitelline space. Hence

335 they lose the balanced orientation. Indeed, when sinking was not in the direction of the

336 major axis, rate was generally abnormally high. These eggs were considered moribund, and

337 removed from the experiments.

338 The model of sinking velocity with equivalent diameter is appropriate, with most 339 egg trajectories close to the average simulated one. The 95\% confident interval, provided 340 from the measured variability in specific gravity from an associated gradient column, 341 together with extreme values of observed egg sizes, embraces the majority of the eggs.

342 Maximum 1 over 10 eggs in only half of the experiments are out of this confident interval.

343 Assessing potential deviation from the spherical equivalent model only slightly modified

344 simulated velocities. Considering this effect could partly explain the temporary low

345 velocities of the sinking eggs of stations Q0553 and Q0559 as they are better included in 346 the new confident interval.

347 For sardine experiments, a rapid decline in sinking velocities was noticed for all the 348 eggs (Fig.5) with apparent convergence to a very low velocity. As compared to the 349 predicted velocities of the model, with observed egg densities from an associated gradient 350 column and egg size measurements, initial observed velocities were 2 to 10 times higher. 351 Final measured velocities were on the opposite lower than the predicted average values, and 352 even lower than the minimum predicted value when this minimum was positive (see 353 experiment at station S0465).

354 To better assess these inconsistencies between observation and model for sardine 355 eggs, the diffusion model introduced in the Material and Method section was used and 
356 optimised on 3 parameters for each single egg of the four experiments. The results are

357 shown on Fig. 6 and reveal that for each egg a solution was found. Surprisingly an egg was

358 even ascending after a first period of sinking in the case of experiment at station R0324.

359 Even in this extreme case an optimised parameter solution was found. The proposed

360 solution is explained by an abnormally far lower specific gravity of the time-invariant part

361 of the egg (embryo + yolk + chorion) as compared to the measured mean specific gravity at

362 this station $\left(-4 \sigma_{\mathrm{T}}\right)$, and a permeability coefficient of the chorion not high enough to allow a

363 rapid equilibrium of the perivitelline space with respect to the initial sinking velocity of the

364 egg. This particular egg is however removed from the later statistical analysis on the 365 parameters since it can be considered as an outlier.

366 The resulting distributions of the optimised parameters presented in Fig.7 reveal a 367 Gaussian distribution for both $\mathrm{P}_{\mathrm{m}}$ and $\delta$ eyc, while $\delta$ pvs looks log-normal with values

368 ranging between 0 and 15. The normality of the distribution for the 2 first parameters was

369 tested and validated using the Shapiro-Wilk test $(\alpha=0.05)$. The estimated average

370 permeability coefficient of the chorion is $\mathrm{P}_{\mathrm{m}}=0.0038 \mathrm{~mm} \cdot \mathrm{s}^{-1}\left(+/-0.00086 \mathrm{~mm} \cdot \mathrm{s}^{-1}\right)$. The

371 average deviation of egg (or embryo+yok+chorion) specific gravity to the average egg

372 specific gravity measured at station is $\delta$ eyc $=0.371 \sigma_{\mathrm{T}}\left(+/-0.873 \sigma_{\mathrm{T}}\right)$.

373 In analogy with Fig.4 for anchovy, Fig.8 displays the average model (velocity and

374 diffusion) estimation as well as confident interval for a single sardine experiment, revealing

375 a good prediction of the model based on the whole population averaged permeability

376 coefficient of the chorion, and specific gravity and size parameters specific to the station. 377

378 Egg specific gravity

379 For anchovy, the average egg specific gravity at station ranges between $20.85 \sigma_{\mathrm{T}}$ at a 
coastal plume station and $25.94 \sigma_{\mathrm{T}}$ offshore. The average standard deviation locally, i.e. at

381 stations, is equal to $0.714(\mathrm{n}=62)$. As in Goarant et al. (2007) the difference between

382 stations tested with an ANOVA was significant. We then tested the effect of the local

383 environment on the egg specific gravity, with surface salinity (average between 3 and $5 \mathrm{~m}$

384 depth), surface density, and equivalent surface density with temperature adjusted to the

385 gradient column temperature (Table 3). Best fit was obtained for both salinity and

386 equivalent density, with in each case an explained variance of $70.4 \%$, whereas for surface

387 density only 55\% is explained with higher residuals and lower $\mathrm{F}$ statistics. The fitted

388 regression is shown on Fig.9 for the equivalent water density, with a slope close to 1,

389 revealing an average negative difference in specific gravity between eggs and surface water

390 of $0.92 \sigma_{\text {T. }}$ At only one station the eggs were on average negatively buoyant in surface

391 waters.

392 For sardine, the average egg specific gravity at station ranges between $22.97 \sigma_{\mathrm{T}}$ at a

393 coastal plume station and 25.78 offshore (Fig.10). The average standard deviation locally,

394 i.e. at station, is equal to $0.832(n=27)$. The difference between stations tested with an

395 ANOVA was significant. We then tested the effect of the local environment on the egg

396 specific gravity, with surface salinity (at 3m depth), surface water density, and equivalent

397 surface density with temperature adjusted to the gradient column temperature (Table 3). We

398 also tested the effect of surface water density on the specific gravity of the eggs after

399 correcting the latter by the thermal expansion coefficient proposed by Coombs et al. (1985).

400 Best fit was obtained when using this thermal expansion coefficient (see also Fig.11), with

401 an explained variance of 60.3\%. As for anchovy, the worst fitted regression was for surface

402 density, but when it was adjusted for temperature of the gradient column, then the fit was

403 similar and even slightly better than for surface salinity. Fig.11 reveals a slope significantly 
404 lower than 1, but again and similarly as for anchovy, on the range of observed values, the 405 negative difference in specific gravity was estimated on average equal to $1.06 \sigma_{\mathrm{T}}$.

406

407 


\section{DISCUSSION}

410 Our study quantifies relationship between both size and specific gravity of fish eggs and

411 their environment, for anchovy and sardine. This is the first time for size in the Bay of

412 Biscay, as well as for specific gravity for sardine. In addition several sinking experiments

413 were conducted allowing robust estimation of the permeability of sardine eggs, while

414 confirming that it can be neglected for anchovy eggs. Despite being taxonomically close, 415 these two species show different characteristics in terms of size, shape and perivitelline 416 space, providing a representative diversity of results that can be useful also for other 417 species. While relationship of size with environment may be highly season and region 418 dependent, that of specific gravity with sea surface density can likely be generalised to 419 other pelagic species spawning in surface layer of stratified regions, as the result of an 420 evolutionary adaptation.

421

422 Egg size

423 The size of anchovy and sardine eggs for the Bay of Biscay in spring are all within the 424 observed range of variability given in Munk and Nielsen (2005). We also provided 425 measurements of vitellus size for sardine and then calculated perivitelline space from the 426 volume difference, neglecting the chorion volume. The chorion volume could not be 427 measured on living eggs onboard, but is assumed to be small for teleosts (1-5\% of total egg 428 volume, Sundby and Kristiansen, 2015). These values are lower than 1 standard deviation

429 of the perivitelline space (6.2\%). But most important for our experiment and analysis is the 430 fact that the chorion volume does not vary through time (Jung et al., 2014). 'At station' 431 variability taken from 20 eggs is logically lower than variability from the whole set of 
measured individuals, and we would recommend using the population estimated variability

433 when generating variability for vertical distribution model purpose, especially when no

434 external factors of variability applies.

435 This does not appear to be the case for sardine, with both its total egg and vitellus

436 diameter decreasing with increasing surface temperature where they were sampled. Neither

437 surface salinity ranging between 24 and $27 \sigma_{\mathrm{T}}$, nor egg specific gravity itself had any effect

438 on the egg size. Looking for potential experimental artifact, thermal expansion of eggs

439 could be thought of, but the results would be the opposite, with increasing temperature

440 increasing the egg volume. Also eggs were always maintained in the sampled surface water

441 until size measurements, preventing volume change from temperature change during

442 experiments. Temperature can accelerate egg development, thus there could be a bias with

443 the vitellus size decreased to the benefit of the embryo. However this should not have any

444 effect on the egg size itself as is observed, and we also made sure to use only early stages of

445 eggs in which embryo development is negligible.

446 In the absence of artifacts, and without any strong reason for direct in-situ

447 temperature effect after spawning (Chambers, 1997), effects during oogenesis or indirectly

448 through maternal influence were preferred as hypothesis. Sampling occurs every year in

449 May, but surface temperature varies a lot at that time of the year (from 12 to $17^{\circ} \mathrm{C}$ at

450 sardine sampling stations), and could either have a biological effect on egg quality, or be a

451 proxy for more or less advanced spawning season. Decrease of the egg size along the

452 spawning season in spring was already described at the population level for sardine in the

453 English Channel (Southward and Demir, 1974) as well as for other clupeoids (Blaxter and

454 Hunter, 1982) This effect was also shown at the individual maternal level for gadoids with

455 egg size decreasing with the number of batches (Chambers and Waiwood, 1996; Kjesbu, 
456 1989; Marteinsdottir and Steinarsson, 1998; Trippel and Neil, 2004; Vallin and Nissling,

457 2000). In the Bay of Biscay sardine spawning in spring occurs from February to June

458 (Stratoudakis et al., 2007) with peak in March-April. May, especially on warm years, would

459 then already be representative of late spawning. Late spawning season generally shows

460 more marked decrease in egg size (Blaxter and Hunter, 1982). This could also explain the

461 lack of observed effect on anchovy, for which May is the peak spawning season (Motos et

462 al., 1996). Riveiro et al. (2004) also noticed a potential effect of temperature on sardine egg

463 size from winter to summer in Galicia. They related this pattern to a correlated decrease of

464 absolute organic content of the eggs, with the following potential ecological significance :

465 bigger eggs with higher reserve content grow faster, which would compensate for slower

466 development in the colder month, eventually enhancing early life stages survival.

467 Unfortunately our type of data does not help for further conclusion on whether temperature

468 has a direct effect during oocyte maturation whatever size, age or condition of the female,

469 or is just a proxy of advancement of the spawning season under an effect of size and/or age

470 structure of the spawning population. Maternal condition hypothesis is unlikely since

471 sardine has its energy density increasing from late winter to summer in the Bay of Biscay

472 (unpublished data). Further sampling of eggs together with biometry analysis of adults in

473 reproduction would help disentangling the direct (oogenesis development time) and

474 maternal effects of temperature on egg size.

475 Egg specific gravity is in part controlled by input of water to the oocyte during the

476 hydration process, under the influence of maternal body fluid (Craik and Harvey, 1987) but

477 ultimately under the influence of external medium salinity as observed between (Solemdal,

478 1967; Thorsen et al., 1996) or within regions (Goarant et al., 2007). Thus one would expect

479 some variation of egg volume related to either water salinity or egg specific gravity, as a 
consequence of higher hydration in low saline areas. This was indeed observed for flounder

481 (Solemdal, 1967) herring (Alderdice et al., 1979) or cod (Kjesbu et al., 1992; Nissling et

482 al., 1994) even if the significance on size was rather low as compared to other impacts on

483 yolk osmolarity or chorion thickness. The relatively low observed variability of water

484 salinity in our study may explain the lack of observed effect on egg size, i.e. change in

485 osmolarity of yolk would imply no or undetectable change of the egg volume for our two

486 species of interest. Comparison with other more contrasted areas such as the Mediterranean

487 sea would be interesting.

489 Sinking velocity

490 Egg size measurements were used as input for the experiments on sinking velocities. The 491 equation of Denny (1993) for anchovy eggs considering a sphere of equivalent volume 492 provides good fit to the observations. The use of a shape correction together with 493 consideration of a variable orientation of the eggs when sinking does not change much the 494 prediction, but widens the possible range of sinking velocities slightly with few more eggs 495 in the confident interval of the model. During the experiment most eggs were falling in the 496 direction of their major axis, a sign of good quality (see result section). Despite removal of 497 most suspicious eggs, there was slight deviations from perfect orientation along the sinking 498 trajectory, which could partly explain the non fully linear sinking rate of certain eggs. 499 Coombs et al. (2004) estimated that correcting for the shape gave a higher velocity but 500 found a lower fit to data than when using the equivalent spherical shape. Boyra et al. (2003) 501 estimated the effect of a shape correction on a vertical distribution model and could not find 502 any significant effect. One possible explanation proposed is that in the field orientation is 503 variable under mixing effect and thus individual effect of a particular orientation can not be 
504 evidenced. Our study also confirms that in a statistical sense the consideration of shape

505 does not significantly improve the prediction and that spherical equivalent volume is a 506 justified approximation. For both species, after permeability correction for sardine (see

507 below), our model of sinking velocity is able to predict both mean and variability of the

508 sinking velocity of the eggs from a given sample.

509

510 Egg permeability

511 The experiments on anchovy sinking velocity did not call for any additional diffusion

512 component between egg and external medium. This was not the case for sardine for which

513 experiments showed a strong decrease of velocity for every single egg. To explain this and

514 considering the properties of the different part of an egg (Craik and Harvey, 1987;

515 Davenport et al., 1981; Jung et al., 2014), the logical hypothesis relies on perivitelline space

516 adjusment in specific gravity to the external medium. Our model of sinking velocity and

517 diffusion through the chorion fits well to the data, at the individual (Fig.6) or sample (Fig.8)

518 scale and then validate this hypothesis.

519 Another confirmation is the normal distribution of the optimised chorion

520 permeability coefficients. We found a mean value of $0.0038 \mathrm{~mm} \cdot \mathrm{s}^{-1}$ to be compared to 0.002

$521 \mathrm{~mm} . \mathrm{s}^{-1}$ found by Coombs et al. (2004) in a similar exercise but on a single experiment with

522 few sardine eggs. Their value lies within our 95\% confident interval and seems in

523 agreement with our study. The values of optimised parameter $\delta$ eyc, which refers to a degree

524 of freedom to take into account 'at station' variability in observed egg specific gravity, also

525 display a normal distribution. Its standard deviation $0.873 \sigma_{\mathrm{T}}$ is really close to the standard

526 deviation $0.832 \sigma_{\mathrm{T}}$ of 'at station' egg specific gravity. The average of $0.371 \sigma_{\mathrm{T}}$ reveals a bias

527 although small as compared to the expected null deviation on average. Indeed, under the 
528 hypothesis that embryo+yolk+chorion do not change in specific gravity in different

529 medium and determine whole egg specific gravity at the equilibrium, average egg specific

530 gravity should be equal in both sinking and density gradient experiments, and thus on

531 average the residuals $\delta$ eyc should equal zero. This parameter is well constrained at the end

532 of the experiment when perivitelline space has come to an equilibrium and only specific

533 gravity of embryo+yolk+chorion determines sinking velocity. It is suspected that in our

534 experiments equilibrium is not always exactly reached when the egg reaches the bottom of

535 the homogeneous column, which could explain this small positive bias. The optimised

536 values of the third parameter $\delta$ pvs were surprising. While values close and centered around

5370 were expected, a somehow uniform distribution with values ranging between $1 \sigma_{\mathrm{T}}$ and

538 almost $15 \sigma_{\mathrm{T}}$ resulted from optimisation. As perivitelline space is about $80 \%$ of the total egg

539 volume, it is excluded that such high values are representative of in-situ situation. It thus

540 means that specific gravity of the perivitelline space has increased significantly between

541 sampling and release in the column. As eggs were maintained in surface sampled water for

542 the whole experimental duration before release in the column, we suspect here loss of water

543 when in contact with air either while floating in the container or when size measured in a

544 water drop. However, this feature has only the effect of increasing the velocity at the

545 beginning of sinking experiment and does not invalidate the diffusion model we used, with

546 the assumption of no exchange with the ovoplasm and strong permeability of the chorion.

547 Figure 11 shows the estimated time for eggs to reach an equilibrium in a typical

548 density gradient column with a typical egg specific gravity found in our area. This reveals

549 that accounting for permeability of the chorion for anchovy is negligible given the small

550 volume of the perivitelline space ( $\sim 5 \%)$. It also shows that convergence to an equilibrium

551 for sardine can take more than twice the time than for anchovy, and that a minimum of 50- 
$55260 \mathrm{mn}$ is a reasonable duration to wait before the first height reading for sardine, as

553 compared to the 20 min duration for anchovy.

554

555 Influence of surface water on egg specific gravity

556 Our study updates the correlation found by Goarant et al. (2007) between anchovy eggs and

557 surface water, and provides the statistics of a similar regression for sardine. Egg specific

558 gravity is determined in the ovary prior to the ovulation under the combined result of

559 oocyte hydration and investment in heavy chorion material (Jung et al., 2014). Oocyte

560 hydration involves yolk proteolysis resulting in increasing oocyte osmolarity (Craik and

561 Harvey, 1987) and water passage through the vitelline membrane using molecular water

562 channels (Fabra et al., 2005).

563 Goarant et al. (2007) found better correlation with salinity than density. We evidenced that

564 this was only because of difference in temperature between sampled water and density

565 gradient column. By correcting for this, i.e. calculating the equivalent surface density at the

566 column temperature, we logically found equivalent statistics for both salinity and density in

567 our dataset. The explained variance (70\%) is of the same order as the one found by Goarant

568 et al. (2007) with a smaller set of data. For sardine, the results are similar, with equivalent

569 density having slightly better statistics than salinity. Using the thermal expansion

570 coefficient proposed by Coombs et al. (1985) for sardine eggs, statistics get even better,

571 with $60 \%$ of the variability explained. From mechanisms behind thermal expansion based

572 on egg constituents, Sundby and Kristiansen (2015) estimated that this effect can in most

573 cases be neglected for egg buoyancy determination. However, given the accuracy of the

574 measurements expected from the density gradient column, having a similar measured

575 thermal expansion coefficient for anchovy eggs would also slightly improve the statistics 
576 for this species. In any case, having or not the specific thermal expansion, our

577 recommendation is to set the temperature of the gradient column to the one of the surface

578 water, in order to maximise the accuracy when assessing relationship with the environment.

579 Our regression confirms that pelagic eggs found in mixed surface layers are 580 positively buoyant, with their vertical distribution at the equilibrium in the field 581 complementary controlled by mixing. In the range of the sampled surface density, the 582 estimated difference in specific gravity between egg and water for anchovy is almost 583 constant, around $-0.92 \sigma_{\mathrm{T}}$. This difference is almost similar for sardine $\left(-1.06 \sigma_{\mathrm{T}}\right)$, but with a 584 slight increasing trend with water density increasing. The regression residuals may have 585 several origins. First, egg specific gravity is known to vary with development for both 586 species (Coombs et al., 1985; Ospina-Álvarez et al., 2012). For a given stage the correlation 587 should not change, but we can not make sure all eggs used in our experiments have the 588 exact same stage. Second, vertical structure of the water column may be really diverse, 589 especially in spring in the vicinity of a river plume like the Gironde. Spawning depth as 590 well as sampling depth is obviously sensitive or in interaction with this structure, and the 591 regression to the 3-5m layer may be affected by this. Third, we can not exclude some

592 experimental effect in the residuals. Even if the impact of perivitelline space was shown 593 limited if caution is taken in the reading procedure of the gradient column, its buffering

594 effect adds some complex processes in the experiment, as well as in the potential 595 equilibrium of the vertical distribution reached in-situ.

597 Interest for modeling application of egg vertical distribution

598 Size is not the most sensitive parameter in vertical distribution model of eggs, but our 599 extensive set of measurements provides useful information on size variability in order to 
601 approximating the anchovy egg with the equivalent spherical volume is relevant, especially

602 when assuming that in-situ orientation of eggs is likely to change under mixing effect.

603 Consideration of the relationship of size with water temperature may also prove useful, for

604 sardine at least in the Bay of Biscay, when simulations have to be made over the spawning

605 season spanning a wide range of temperature. This temperature effect may also be

606 informative for bioenergetics models, since relative biochemical composition is rather

607 stable between eggs and thus the bigger it is the more energy it generally contains.

608 Egg specific gravity is the most sensitive factor determining position of eggs in the

609 water column. Taking into account its relationship with local water density or salinity is

610 also key, otherwise simulated eggs may be stuck at surface or rapidly fall at the bottom

611 based on existing coastal gradients in the vicinity of plume areas. Salinity is only useful if

612 the correction of temperature is applied, otherwise inconsistency between the specific

613 gravities of the egg and local water may occur. Thus we recommend using directly the

614 proposed regression with density, even more that it seems generic enough to be applied

615 across regions (Ospina-Álvarez et al., 2012). Our study provides an update of it for

616 anchovy, and a new parameterisation for sardine, together with associated 'at station'

617 variability, again useful in reproducing correctly observed vertical distributions. These

618 regressions are valid for first stages of egg and set the egg specific gravity at spawning, or

619 initial condition in a model. Then, models of vertical distribution and drift need to consider

620 relative change in the specific gravity through development (Ospina-Álvarez et al., 2012).

621 Including permeability of the chorion in dynamic models of egg vertical distribution for

622 species with large perivitelline space may also prove necessary to eventually improve

623 accuracy of dispersal modelling results, but needs to be verified against in-situ field data. 


\section{ACKNOWLEDGEMENTS}

625 The authors would like to thank J. Massé and M. Doray the chief scientists of the PELGAS

626 surveys, as well as the crew of the R/V Thalassa for help in egg sampling. We also thank

627 two anonymous reviewers for their constructive comments. This work was supported by

628 successive research programs and among them the project SEAMAN of the ANR and EU

629 FP7 ERA-NET SEASERA. 
Adlandsvik, B., 1998. VertEgg-User Manual, Fisken og Havet. Institute of Marine Research, Bergen.

Adlandsvik, B., Coombs, S., Sundby, S., Temple, G., 2001. Buoyancy and vertical distribution of eggs and larvae of blue whiting (Micromesistius poutassou): observations and modelling. Fish. Res. 50, 59-72.

Ahlstrom, E., 1943. Studies on the Pacific pilchard or sardine (Sardinops caeculea). 4. Influence of temperature on the rate of development of pilchard eggs in nature. (No. 23), U.S. Fish. Wildt. Secv.,spec. sci. rep.

Alderdice, D.F., Rosenthal, H., Velsen, F.P.J., 1979. Influence of salinity and cadmium on the volume of Pacific herring eggs. Helgoländer Wiss. Meeresunters. 32, 163-178.

Blaxter, J.H.S. and Hunter, J.R. (1982) The Biology of the Clupeoid Fishes. Advances in Marine Biology. 20:1-223.

Bourriau, P., 1991. The “'Carre Net”” (No. ICES CM 1991/L:53).

Boyra, G., Rueda, L., Coombs, S., Sundby, S., Adlandsvik, B., Santos, M., Uriarte, A., 2003. Modelling the vertical distribution of eggs of anchovy (Engraulis encrasicolus) and sardine (Sardina pilchardus). Fish. Oceanogr. 12, 381-395.

Byrd, R.H., Lu, P., Nocedal, J., Zhu, C., 1995. A limited memory algorithm for bound constrained optimization. SIAM J. Scientific Computing 16, 1190-1208.

Chambers, R.C., 1997. Environmental influences on egg and propagule sizes in marine fishes, in: Early Life History and Recruitment in Fish Populations. R.C. Chambers and E.A. Trippel, New York, Chapman \& Hall, pp. 63-102.

Chambers, R.C., Waiwood, K.G., 1996. Maternal and seasonal differences in egg sizes and 
spawning characteristics of captive Atlantic cod, Gadus morhua. Can. J. Fish. Aquat. Sci. 53, 1986-2003.

Checkley Jr, D.M., Ortner, P.B., Settle, L.R., Cummings, S.R., 1997. A continuous, underway fish egg sampler. Fish. Oceanogr. 6, 58-73.

Coombs, S.H., 1981. A density-gradient column for determining the specific gravity of fish eggs, with particular reference to eggs of the mackerel Scomber scombrus. Mar. Biol. 63, 101-106.

Coombs, S.H., Boyra, G., Rueda, L.D., Uriarte, A., Santos, M., Conway, D.V.P., Halliday, N.C., 2004. Buoyancy measurements and vertical distribution of eggs of sardine (Sardina pilchardus) and anchovy (Engraulis encrasicolus). Mar. Biol. 145, 959970.

Coombs, S.H., Fosh, C.A., Keen, M.A., 1985. The buoyancy and vertical distribution of eggs of sprat (Sprattus Sprattus) and pilchard (Sardina Pilchardus). J. Mar. Biol. Assoc. UK 65, 461-474.

Coombs, S., Nichols, J., Fosh, C., 1990. Plaice eggs (Pleuronectes platessa L.) in the southern North-Sea : abundance, spawning area, vertical distribution, and buoyancy. J. Cons. 47, 133-139.

Craik, J.C.A., Harvey, S.M., 1987. The causes of buoyancy in eggs of marine teleosts. J. Mar. Biol. Assoc. U. K. 67, 169-182.

Curtis, A.K., Checkley, D.M., Pepin, P., 2007. Predicting the vertical profiles of anchovy (Engraulis mordax) and sardine (Sardinops sagax) eggs in the California Current System. Fish. Oceanogr. 16, 68-84.

Dalavalle, J.M., 1948. Dynamics of small particles, in: Micromeristics: The Technology of Fine Particles. Pitman, New York, pp. 11-30. 
Davenport, J., Lønning, S., Kjørsvik, E., 1981. Osmotic and structural changes during early development of eggs and larvae of the cod, Gadus morhua L. J. Fish Biol. 19, 317331.

Denny, M., 1993. Air and Water: the Biology and Physics of Life’s Media. Princeton, NJ: Princeton University Press, 341 pp.

Fabra, M., Raldúa, D., Power, D.M., Deen, P.M.T., Cerdà, J., 2005. Marine fish egg hydration is Aquaporin-mediated. Science 307, 545-545.

Goarant, A., Petitgas, P., Bourriau, P., 2007. Anchovy (Engraulis encrasicolus) egg density measurements in the Bay of Biscay: evidence for the spatial variation in egg density with sea surface salinity. Mar. Biol. 151, 1907-1915.

Huret, M., Petitgas, P., Woillez, M., 2010. Dispersal kernels and their drivers captured with a hydrodynamic model and spatial indices: A case study on anchovy (Engraulis encrasicolus) early life stages in the Bay of Biscay. Prog. Oceanogr. 87, 6-17.

Hutchinson, G., 1967. The hydrodynamics of the plankton, in: A Treatise of Limnology. Vol. II (Ch.20). G. Hutchinson (Ed.), New York, John Wiley and Sons, pp. 245-305.

Jung, K.-M., Folkvord, A., Kjesbu, O.S., Sundby, S., 2014. Experimental parameterisation of principal physics in buoyancy variations of marine teleost eggs. PLoS ONE 9, e104089.

Kjesbu, O.S., 1989. The spawning activity of cod, Gadus morhua L. J. Fish Biol. 34, 195206.

Kjesbu, O.S., Kryvi, H., Sundby, S., Solemdal, P., 1992. Buoyancy variations in eggs of Atlantic cod (Gadus morhua L.) in relation to chorion thickness and egg size: theory and observations. J. Fish Biol. 41, 581-599.

Marteinsdottir, G., Steinarsson, A., 1998. Maternal influence on the size and viability of 
Iceland cod Gadus morhua eggs and larvae. J. Fish Biol. 52, 1241-1258.

Moser, H.G. and Ahlstrom, E.H. (1985) Staging Anchovy Eggs. In: R. Lasker (ed.), An Egg Production Method for Estimating Spawning Biomass of Pelagic Fish: Application to the Northern Anchovy, Engraulis mordax. NOAA Tech. Rep. NMFS 36. US. Dep. Commer., Wash., D.C., pp.37-41.

Motos, L., Uriarte, A., Valencia, V., 1996. The spawning environment of the Bay of Biscay anchovy (Engraulis encrasicolus L.). Sci. Mar. 60, 117-140.

Munk, P., Nielsen, J.G., 2005. Description of the early stages of each species. In: Eggs and larvae of North Sea fishes. Edited by Munk P. and Nielsen J.G. Biofolia, Frederiksberg, Denmark, 2005, 215 pp.

Nissling, A., Kryvi, H., Vallin, L., 1994. Variation in egg buoyancy of Baltic cod GadusMorhua and its implications for egg survival in prevailing conditions in the Baltic Sea. Mar. Ecol. Prog. Ser. 110, 67-74.

Ospina-Álvarez, A., Palomera, I., Parada, C., 2012. Changes in egg buoyancy during development and its effects on the vertical distribution of anchovy eggs. Fish. Res. 117-118, 86-95.

Parada, C., van der Lingen, C.D., Mullon, C., Penven, P., 2003. Modelling the effect of buoyancy on the transport of anchovy (Engraulis capensis) eggs from spawning to nursery grounds in the southern Benguela: an IBM approach. Fish. Oceanogr. 12, $170-184$.

Petitgas, P., Goarant, A., Masse, J., Bourriau, P., 2009. Combining acoustic and CUFES data for the quality control of fish-stock survey estimates. ICES J. Mar. Sci. 66, $1384-1390$.

Petitgas, P., Magri, S., Lazure, P., 2006. One-dimensional biophysical modelling of fish egg 
vertical distributions in shelf seas. Fish. Oceanogr. 15, 413-428.

Riveiro, I., Guisande, C., Maneiro, I., Vergara, A.R., 2004. Parental effects in the European sardine Sardina pilchardus. Mar. Ecol. Prog. Ser. 274, 225-234.

Solemdal, P., 1967. The effect of salinity on buoyancy, size and development of flounder eggs. Sarsia 29, 431-442.

Southward, A.J., Demir, N., 1974. Seasonal changes in dimensions and viability of the developing eggs of the Cornish pilchard (Sardina pilchardus, Walbaum) off Plymouth, in: The Early Life History of Fish. J. H. S. Blaxter (ed.), Berlin, Springer-Verlag, pp. 53-68.

Stratoudakis, Y., Coombs, S., de Lanzós, A.L., Halliday, N., Costas, G., Caneco, B., Franco, C., Conway, D., Santos, M.B., Silva, A., Bernal, M., 2007. Sardine (Sardina pilchardus) spawning seasonality in European waters of the northeast Atlantic. Mar. Biol. 152, 201-212.

Sundby, S., 1983. A one-dimensional model for the vertical distribution of pelagic fish eggs in the mixed layer. Deep Sea Res. Part Oceanogr. Res. Pap. 30, 645-661.

Sundby, S., Kristiansen, T., 2015. The principles of buoyancy in marine fish eggs and their vertical distributions across the world oceans. PLoS ONE 10, e0138821.

Thorsen, A., Kjesbu, O.S., Fyhn, H.J., Solemdal, P., 1996. Physiological mechanisms of buoyancy in eggs from brackish water cod. J. Fish Biol. 48, 457-477.

Trippel, E.A., Neil, S.R.E., 2004. Maternal and seasonal differences in egg sizes and spawning activity of northwest Atlantic haddock (Melanogrammus aeglefinus) in relation to body size and condition. Can. J. Fish. Aquat. Sci. 61, 2097-2110.

Vallin, L., Nissling, A., 2000. Maternal effects on egg size and egg buoyancy of Baltic cod, Gadus morhua: Implications for stock structure effects on recruitment. Fish. Res. 
49, 21-37.

632 
634

635

636 Table 1. Statistics of egg size. Average sample ('at station') variability (standard deviation)

637 is given in brackets, with $\mathrm{n}_{\mathrm{st}}$ the number of stations.

\begin{tabular}{|l|l|l|l|l|}
\hline & $\begin{array}{l}\text { Diameter (sardine) or } \\
\text { equivalent diameter } \\
\text { (anchovy) }\end{array}$ & Vitellus diameter & Diameter (major axis) & Diameter (minor axis) \\
\hline Anchovy & $\begin{array}{l}0.855+/-0.050, \mathrm{n}=1127 \\
\left(+/-0.036, \mathrm{n}_{\mathrm{st}}=48\right)\end{array}$ & $1.428+/-0.101, \mathrm{n}=1130$ & $0.662+/-0.049, \mathrm{n}=1131$ \\
\hline Sardine & $\begin{array}{l}1.608+/-0.113, \mathrm{n}=587 \\
\left(+/-0.095, \mathrm{n}_{\mathrm{st}}=28\right)\end{array}$ & $\begin{array}{l}0.964+/-0.084, \mathrm{n}=270 \\
\left(+/-0.055, \mathrm{n}_{\mathrm{st}}=13\right)\end{array}$ & & \\
\hline 638 & & & & \\
\hline
\end{tabular}

639 
641 Table 2. Statistics for different regression models between size of sardine eggs and

642 environment covariates or egg specific gravity, based on 27 sampled stations. $\left(^{*}\right)$ indicates

643 significativity of the model for $\mathrm{p}<0.05$.

\begin{tabular}{|l|c|c|c|c|c|}
\hline Covariate & Parameter & Estimate & p-value & F statistics & $\mathrm{R}^{2}$ \\
\hline Sea surface salinity & $\alpha$ (slope) & -0.003 & 0.88 & 0.02 & 0.001 \\
\cline { 2 - 6 } & $\beta$ (intercept) & 1.700 & & & \\
\hline Sea surface temperature & $\alpha$ & -0.018 & $0.0171^{*}$ & 6.53 & 0.207 \\
\cline { 2 - 6 } & $\beta$ & 1.877 & & & 0.004 \\
\hline \multirow{2}{*}{ Egg specific gravity } & $\alpha$ & 0.002 & 0.920 & 0.01 & \\
\hline
\end{tabular}

644

645 
647 Table 3. Statistics for different regression models between specific gravity of anchovy eggs

648 and environment covariates, based on 62 sampled stations. All models are significant for

$649 \mathrm{p}<0.01$.

\begin{tabular}{|l|c|c|c|c|}
\hline Covariate & Parameter & Estimate & F statistics & $\mathrm{R}^{2}$ \\
\hline Salinity & $\alpha$ (slope) & 0.85 & 142.9 & 0.704 \\
\cline { 2 - 5 } & $\beta$ (intercept) & -4.58 & & \\
\hline \multirow{2}{*}{ Density } & $\alpha$ & 0.83 & 72.7 & 0.548 \\
\cline { 2 - 5 } & $\beta$ & 3.55 & 143 & 0.704 \\
\hline Equivalent density at gradient & $\alpha$ & 1.1 & \\
\hline \multirow{2}{*}{ column temperature (Fig.9) } & $\beta$ & -3.43 & & \\
\hline
\end{tabular}

650

651 
653 Table 4. Statistics for different regression models between specific gravity of sardine egg

654 and environment covariates with different corrections, based on 27 sampled stations. All

655 models are significant for $\mathrm{p}<0.01$.

\begin{tabular}{|l|c|c|c|c|}
\hline Covariate & Parameter & Estimate & F statistics & $\mathrm{R}^{2}$ \\
\hline \multirow{2}{*}{ Salinity } & $\alpha$ (slope) & 0.584 & 27.99 & 0.528 \\
\cline { 2 - 5 } & $\beta$ (intercept) & 4.339 & & \\
\hline \multirow{2}{*}{ Density } & $\alpha$ & 0.538 & 14.55 & 0.368 \\
\hline \multirow{2}{*}{ Density with egg specific gravity } & $\beta$ & 10.59 & & \\
\cline { 2 - 5 } & $\alpha$ & 0.748 & 38 & 0.603 \\
\hline Corrected from thermal expansion (Fig.10) & $\beta$ & 5.343 & & \\
\hline Equivalent density at gradient column & $\alpha$ & 0.730 & 28.72 & 0.535 \\
\hline \multirow{2}{*}{ temperature } & $\beta$ & 5.751 & & \\
\hline
\end{tabular}

656

657

658 
Fig.1. Location of stations with egg sampling in the Bay of Biscay. Stations with anchovy

(a) and sardine (b) eggs used in the experiments, with corresponding sampling year.

Isobaths 100, 200, 500, 1000 and 2000 are drawn, and upper left panel shows the general location of the Bay of Biscay in the Northeast Atlantic..

Fig.2. Diameter of anchovy eggs. Mean values over 20 eggs per station are plotted with associated standard deviation, for long axis (left) and min axis (right).

Fig.3. Diameter of sardine eggs (left) and vitellus (right). Mean values over 20 eggs per station are plotted with associated standard deviation.

Fig.4. Sinking experiments for anchovy eggs from six stations. Anchovy egg positions are plotted over time (dotted lines) in homogeneous density columns. Title of each panel is the name of the station, with values between brackets the density of the column and the mean egg specific gravity at station $\left(\sigma_{\mathrm{T}}\right)$, as measured in a gradient column (other set of 50 eggs from same sample). Continuous lines are for calculated velocities based on the mean egg specific gravity and mean equivalent egg diameter, dashed lines for mean specific gravity +/- 2 standard deviation, and max/min equivalent egg diameter, respectively. Grey dashed lines represent uncertainty associated to the variable inclination of the egg when sinking (after Hutchinson, 1967). Note the different scales of the axis between experiments, due to a smaller experiment duration for the 3 last.

Fig.5. Sinking experiments for sardine eggs from 4 stations. Sinking velocity profiles are 
plotted (dotted lines) for 10 eggs in homogeneous columns. Name of station is given as panel title. Continuous lines are for calculated velocity based on mean egg specific gravity measured in an associated gradient column (other set of 50 eggs) with average egg diameter. Dashed lines are for mean specific gravity +/- 2 standard deviation, and max/min egg diameter, respectively.

Fig.6. Sinking model fitting to each single sardine egg from 4 stations. Sardine egg positions are plotted over time (empty circles) in homogeneous density columns. Title of each panel is the name of the station, with values between brackets the density of the column and the mean egg specific gravity at station $\left(\sigma_{\mathrm{T}}\right)$, as measured in a gradient column (other set of 50 eggs from same sample). Continuous lines are simulated velocities by the fitted model with parameters optimised for each egg trajectory (see text).

Fig.7. Probability density of optimised parameters of the model of sinking velocity for each sardine egg of the 4 experiments of Fig.6. (a) Coefficient of permeability of the chorion $\mathrm{P}_{\mathrm{m}}$, (b) difference in specific gravity just before release in the homogeneous column between perivitelline space and egg (סpvs) and (c) between embryo and average specific gravity of the eggs measured in the associated gradient column (Seyc) . Continuous lines are fitted gaussian distributions.

Fig.8. Sinking model result for experiment on sardine eggs from station S0465. Continuous lines are for calculated velocity based on mean egg specific gravity measured in the gradient column (other set of 50 eggs) and mean egg diameter, dashed lines for mean 
specific gravity $+/-1$ standard deviation, and max/min egg diameter, with the following optimised parameters : permeability of chorion $\left(\mathrm{P}_{\mathrm{m}}\right.$ averaged over all eggs of all experiments) and average difference in specific gravity at this station between the perivitelline space and the averaged measured specific gravity (at station $\delta p v s$ ) .

Fig.9. Relation between anchovy egg specific gravity and sea surface density. The mean egg specific gravity $\left(\sigma_{\mathrm{T}}\right)$ is plotted with associated $95 \%$ confident interval calculated locally at each station. The equivalent sea surface (3-5 m) density at the temperature of the density column experiment is given. The continuous line is the fitted linear regression (see Table 3), and the dotted one is the $\mathrm{y}=\mathrm{x}$ line.

Fig.10. Relation between sardine egg specific gravity and sea surface density. The mean equivalent egg specific gravity $\left(\sigma_{\mathrm{T}}\right)$ is plotted with associated $95 \%$ confident interval calculated locally at each station. It is corrected from thermal expansion (from Coombs, 1985). The continuous line is the fitted linear regression (see Table 4), and the dotted one is the $\mathrm{y}=\mathrm{x}$ line.

Fig.11. Simulation of time to neutral buoyancy in a gradient column for an anchovy and a sardine egg with same specific gravity. The minimum and maximum density of the column are $19 \sigma_{\mathrm{T}}$ and $29 \sigma_{\mathrm{T}}$, respectively. The specific gravity of the egg is $24.5 \sigma_{\mathrm{T}}$. Dotted and dash-dotted curves are for an anchovy egg with and without permeability of the chorion $\left(P_{m}=0.0038 \mathrm{~mm} \cdot \mathrm{s}^{-1}\right)$. Continuous and dashed curves are for sardine egg with average $\mathrm{P}_{\mathrm{m}}$ and $\mathrm{P}_{\mathrm{m}}+/-2$ s.d., respectively. Vertical lines indicate the timing when specific gravity of eggs comes closer to the known specific gravity than the given gradient column resolution (0.04 
$\sigma_{\mathrm{T}}$. 

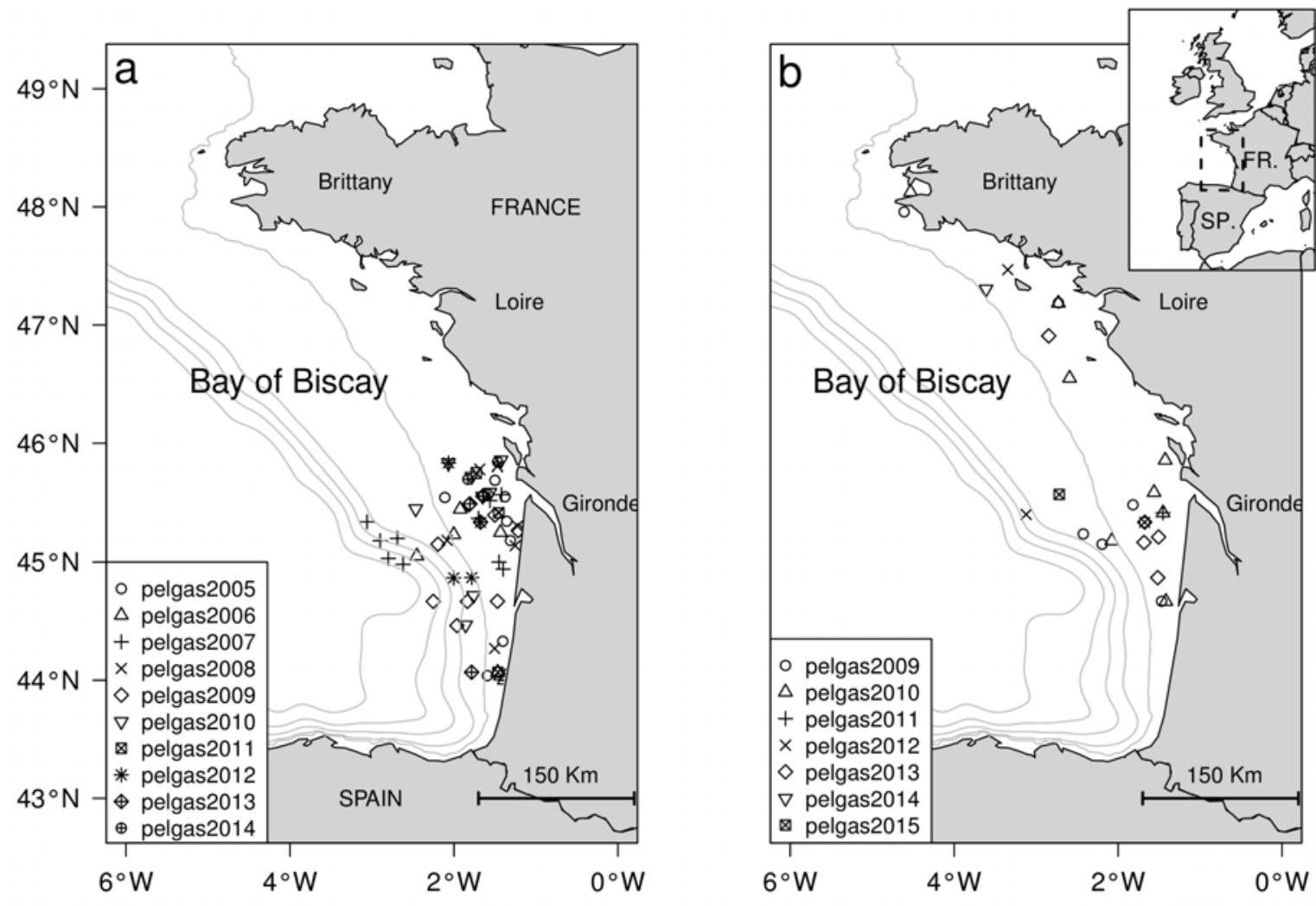

Fig.1 

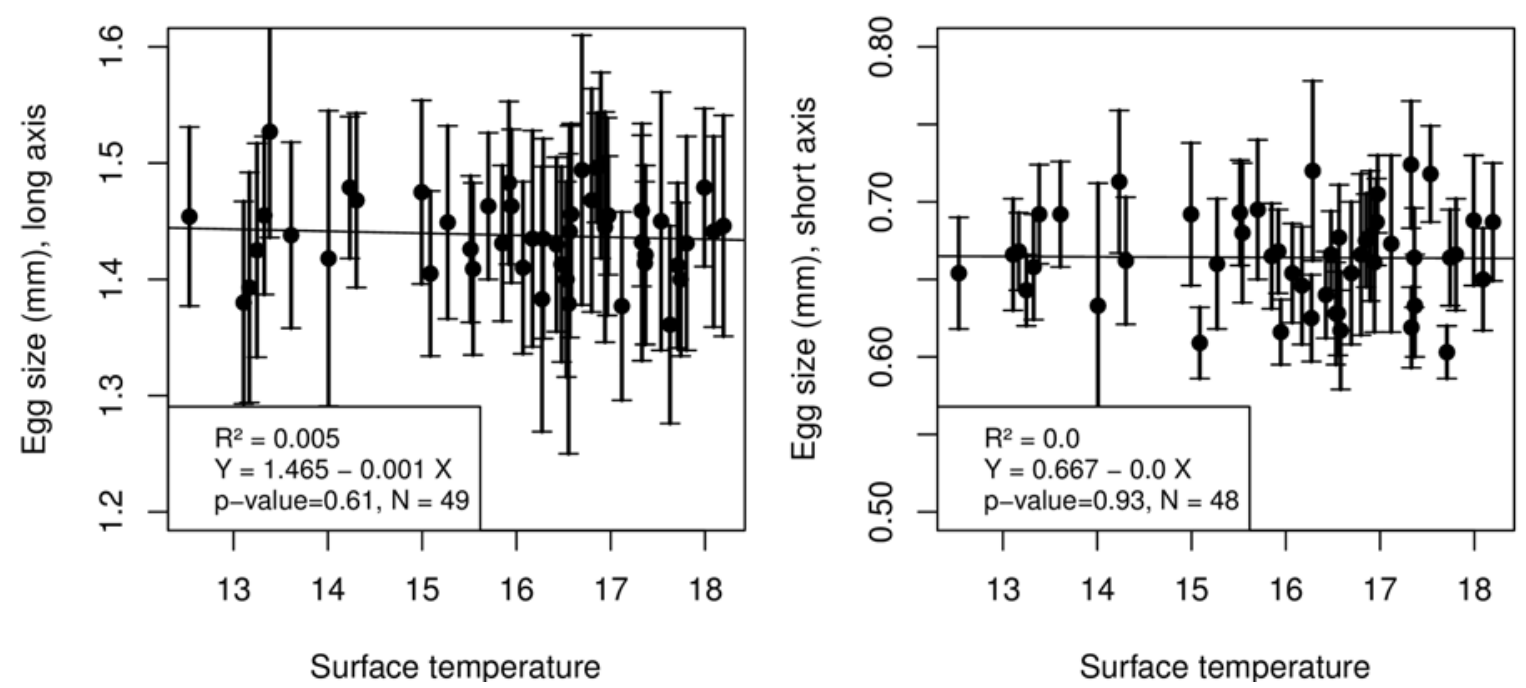

Fig.2
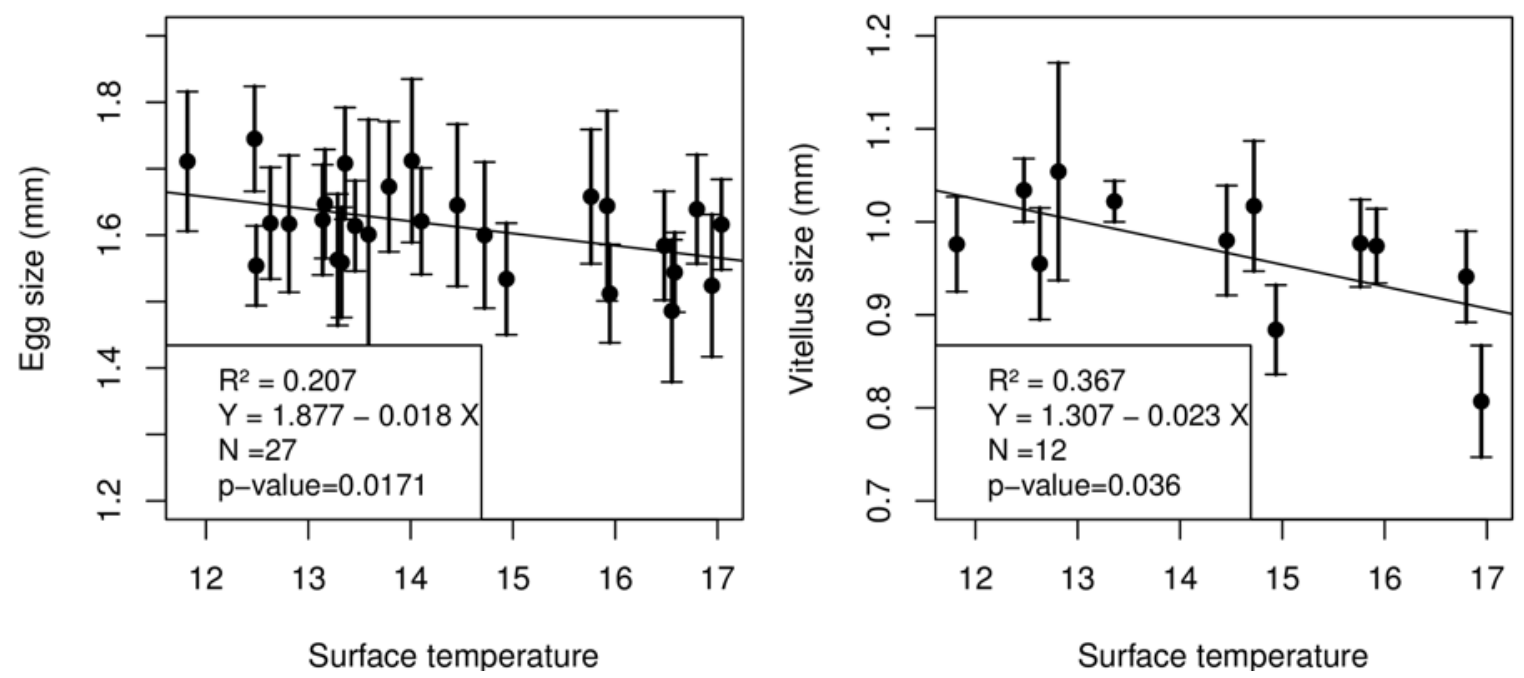

Fig.3 

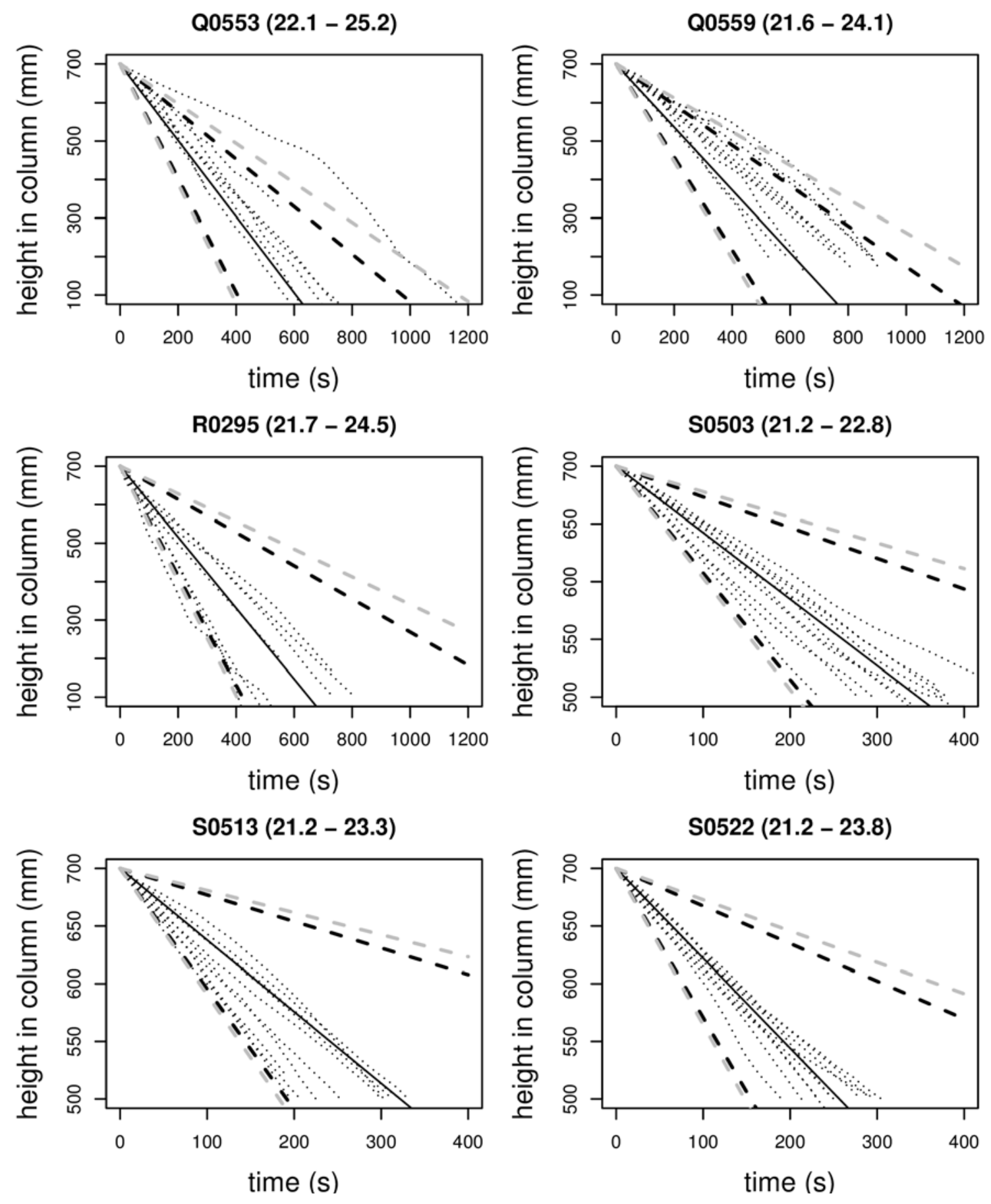

Fig.4 

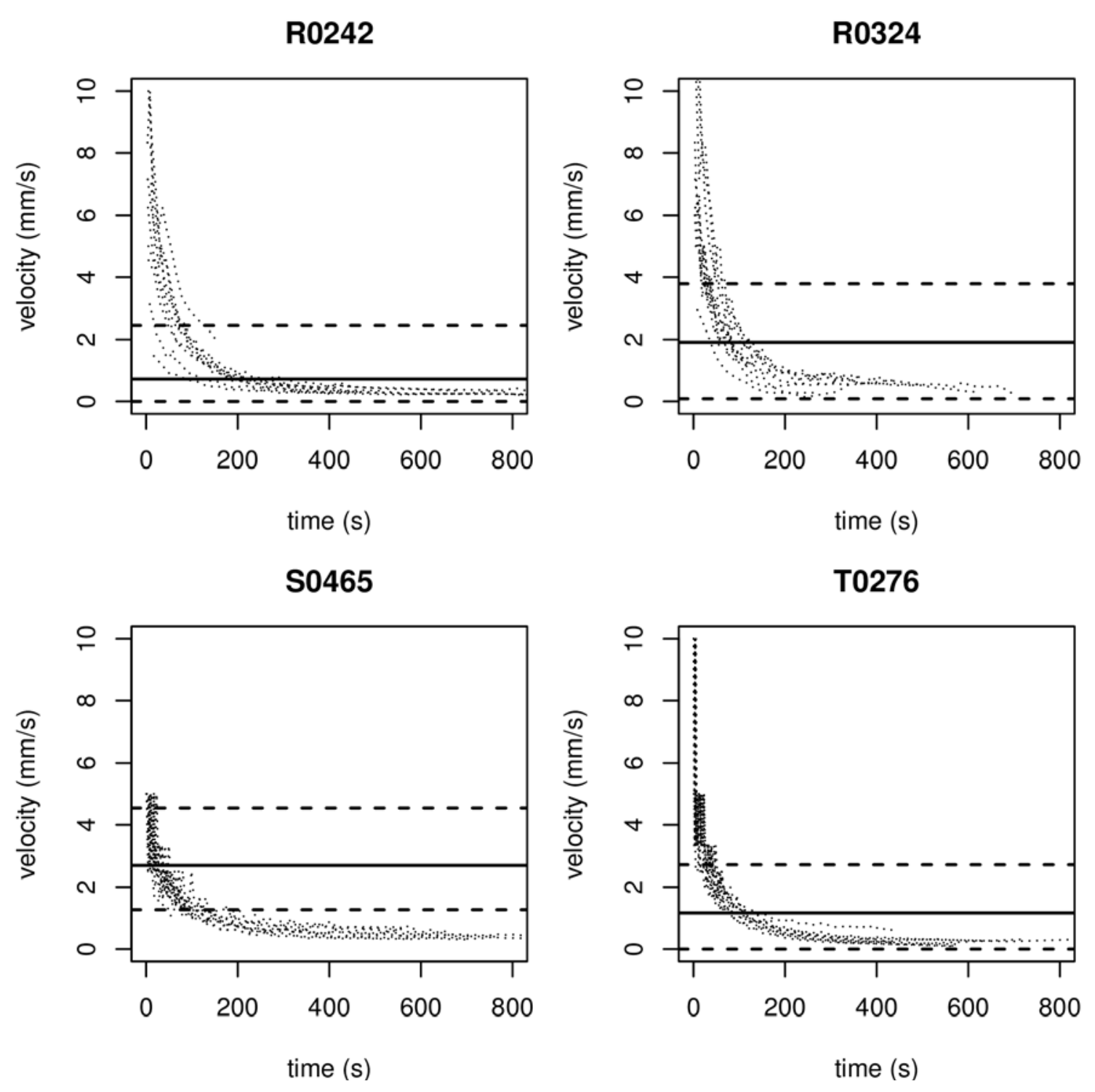

Fig.5 

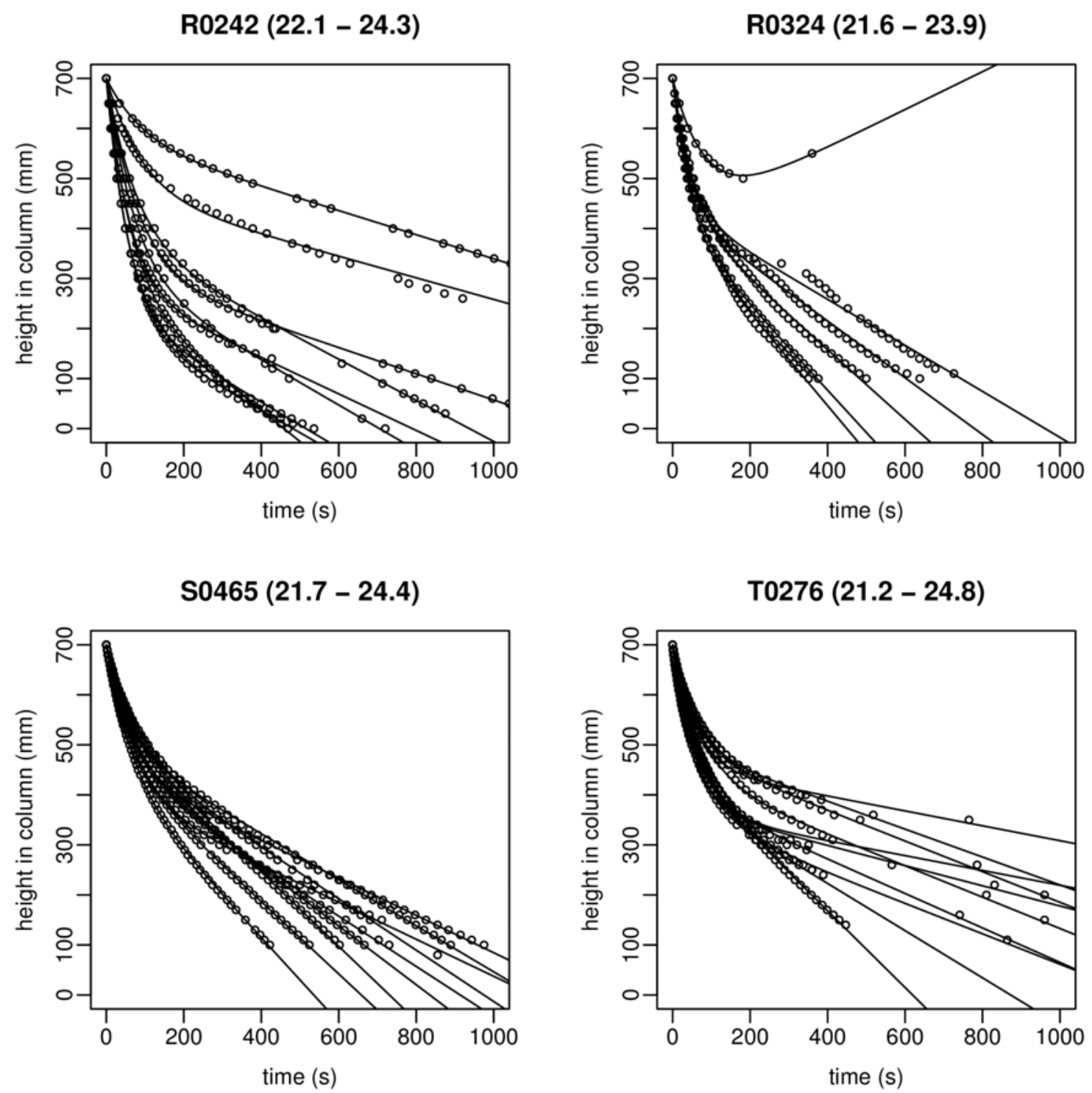

Fig.6 

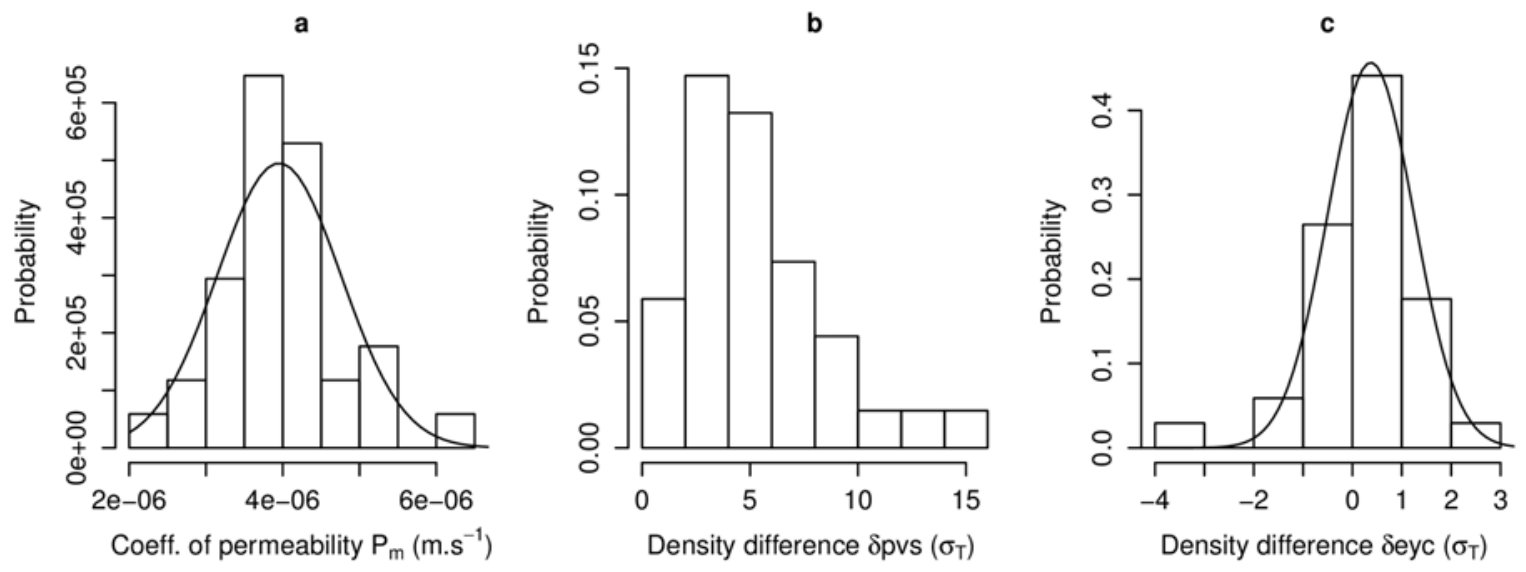

Fig.7 
Fig.8

S0465

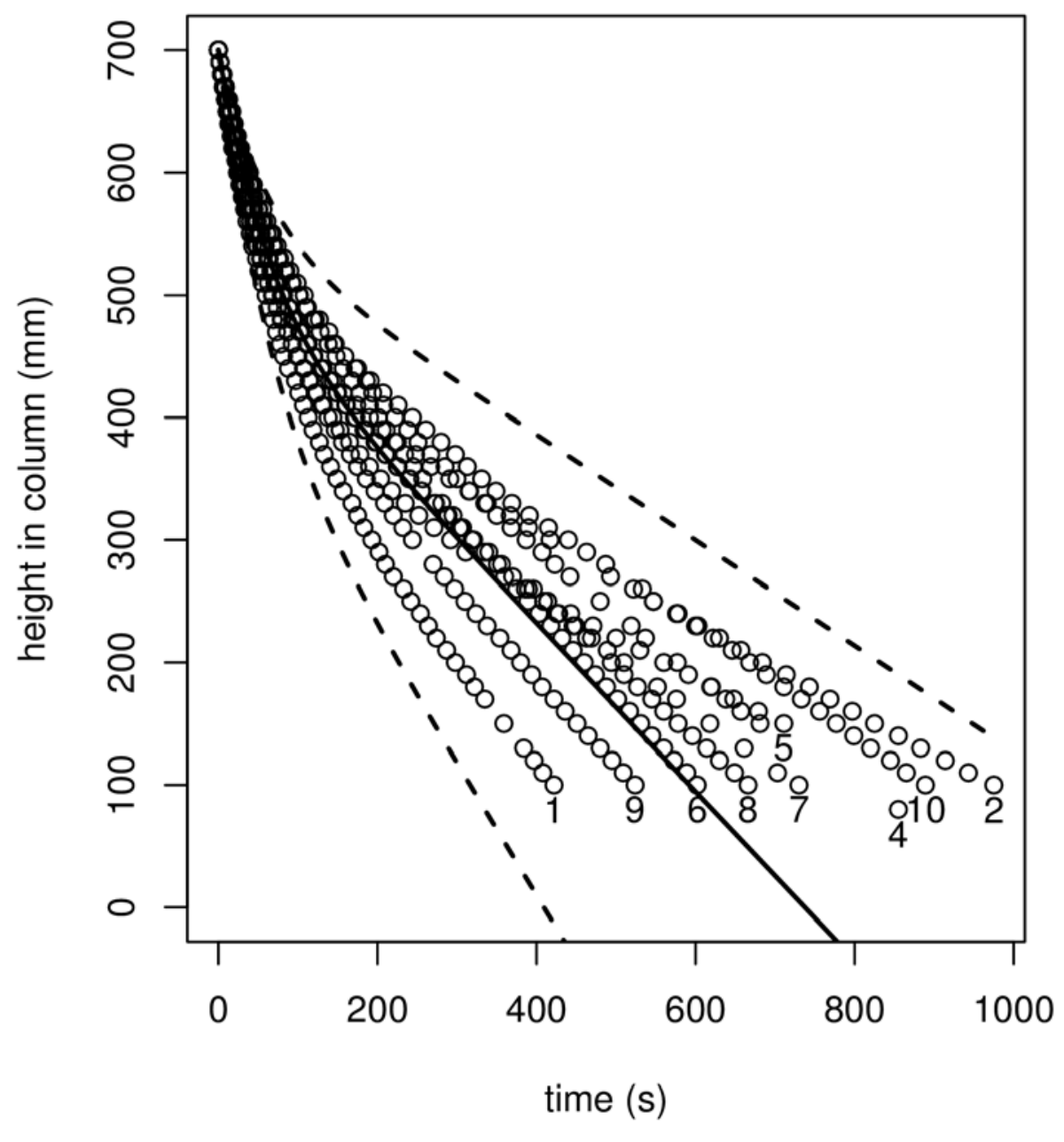


Fig.9

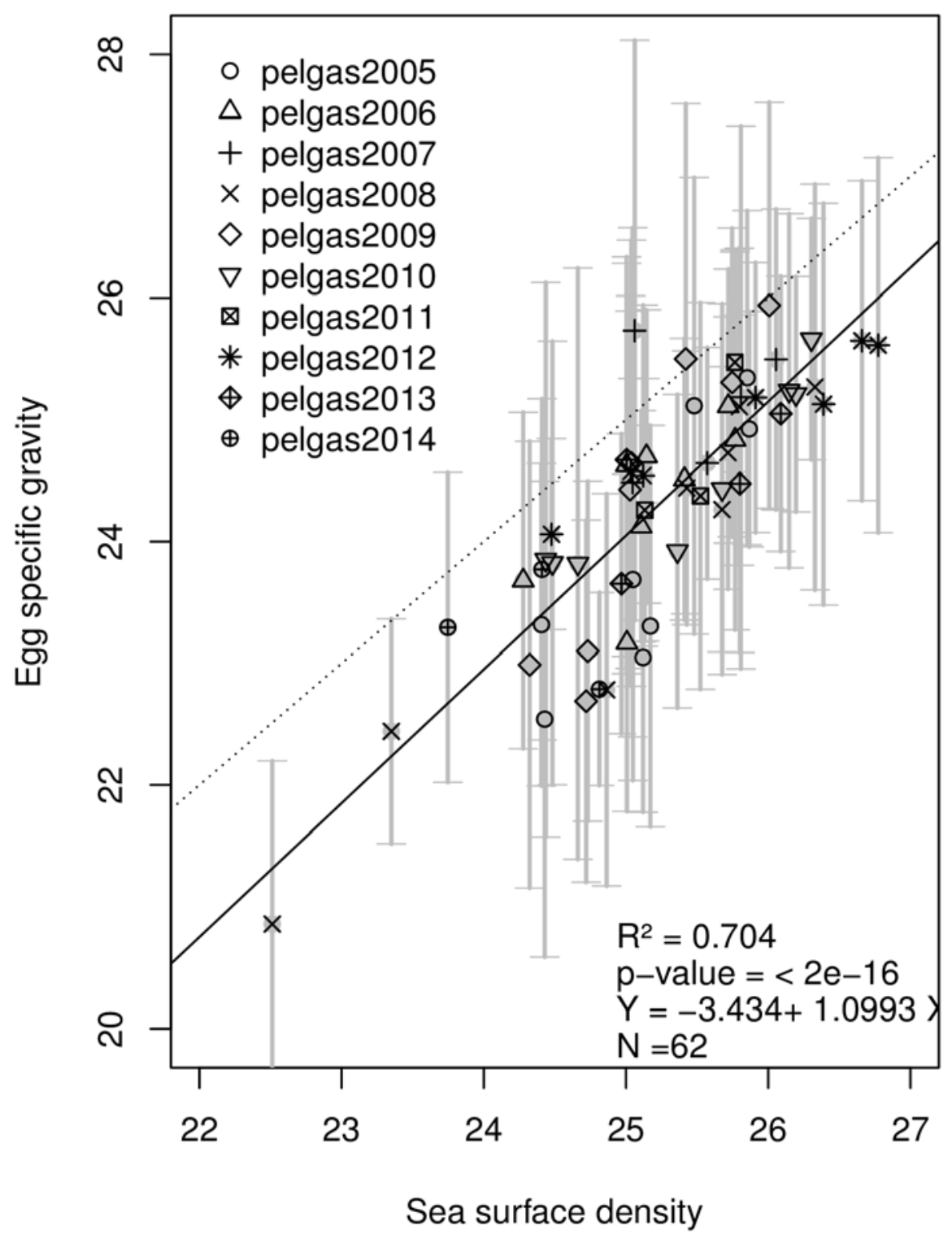


Fig.10

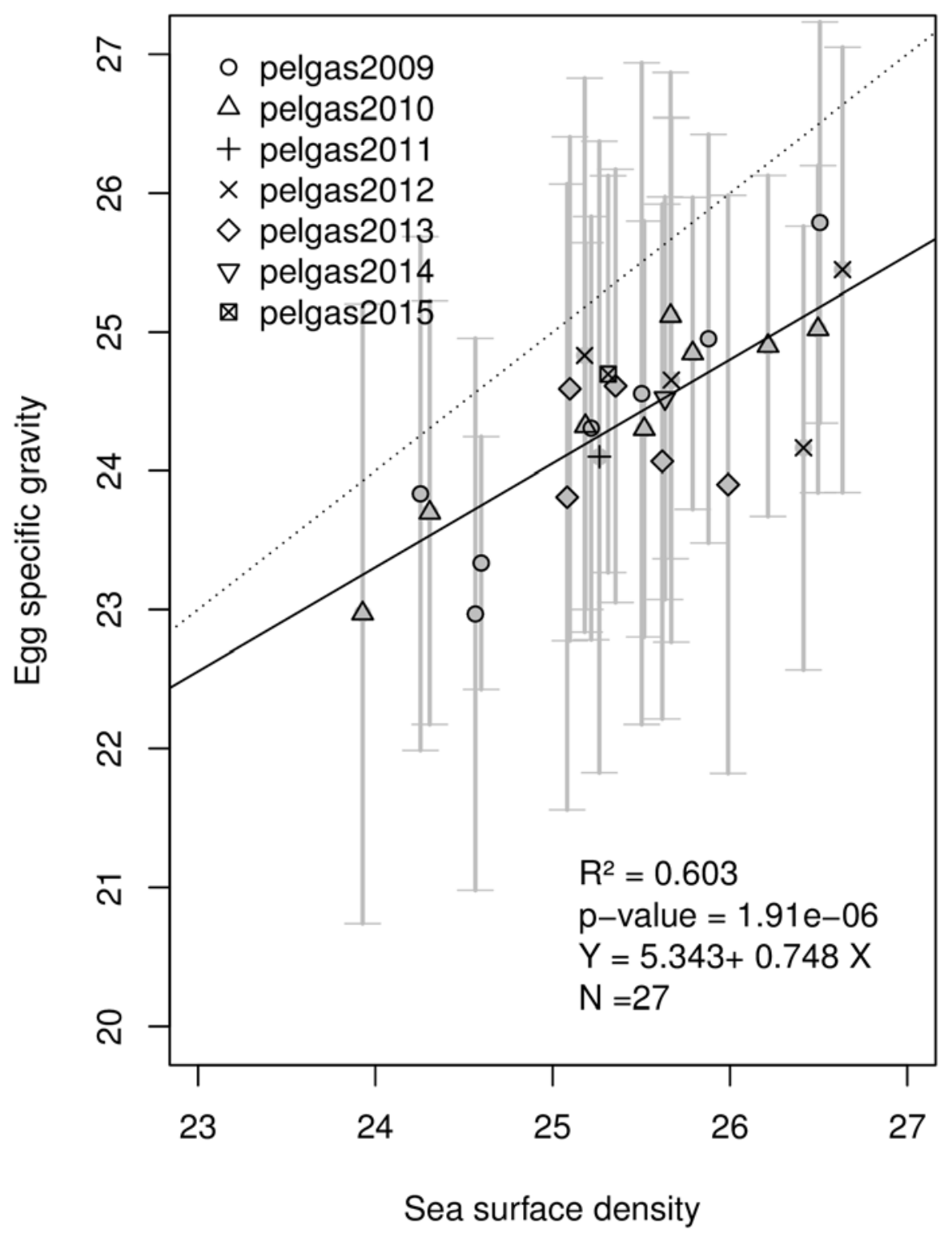




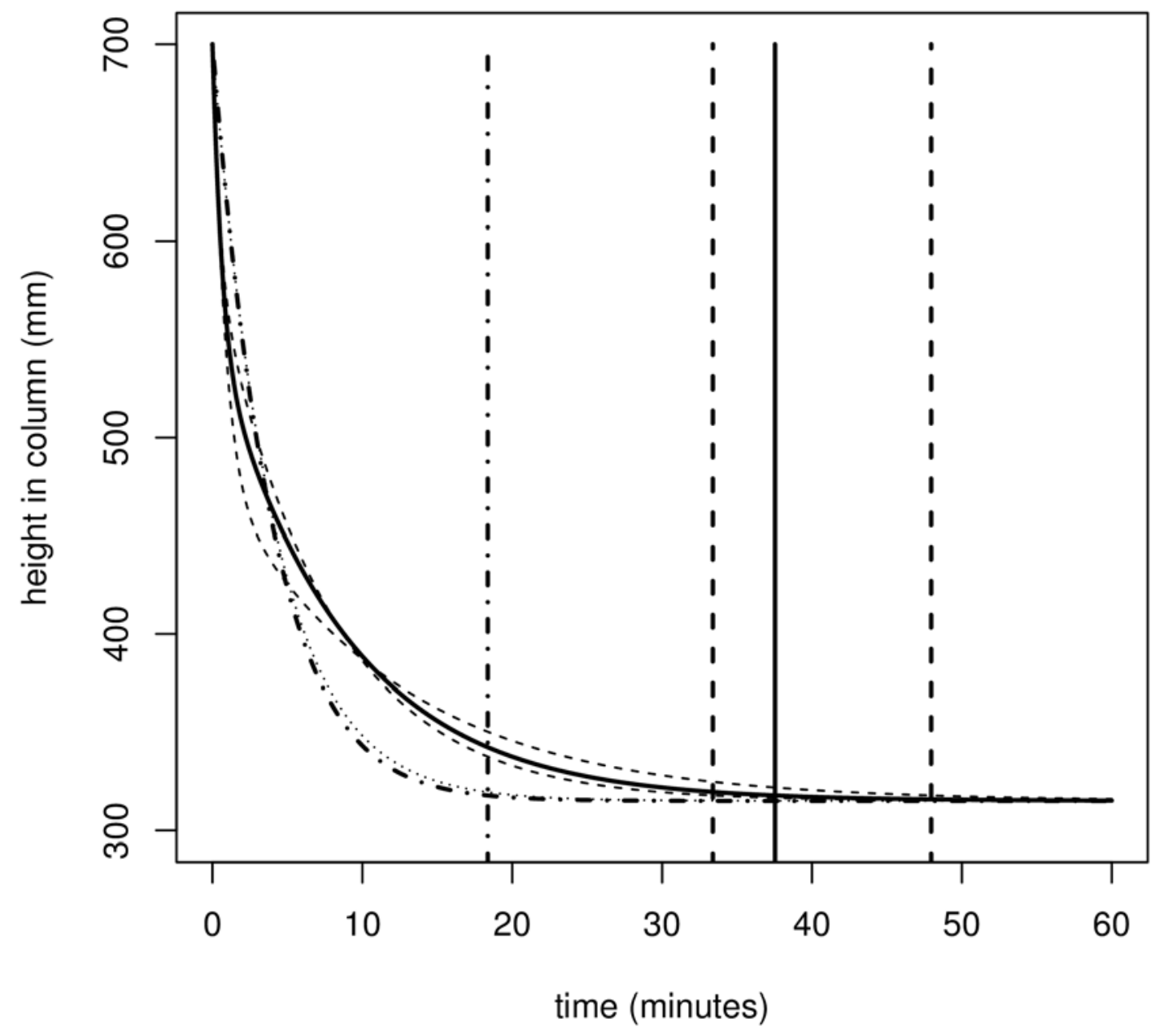

Fig.11 